\title{
Scientific and Technical Aspects of Interference Fits Hydropress Assembling Automation Using Mechatronic Press
}

\author{
Alexander Romanov ${ }^{1}{ }^{*}$, Alexey Shchenyatsky ${ }^{1}$, and Oxana Zorina ${ }^{1}$ \\ ${ }^{1}$ Kalashnikov Izhevsk State Technical University, 7, Studencheskaya street, Izhevsk, 426069, Russia
}

\begin{abstract}
The study object - technological process of interference fits assembling is identified, the scheme with oil supply from the end face is adopted as the technological scheme. Technological pressing equipment is considered, its applicability for hydropress assembling is evaluated. The main aspects of hydropress joints assembling on a base of mechatronic press are established: increasing of assembling performance, its stability. Mathematical models and an algorithm that regulate the process of liquid friction and formation of an oil layer between the contacting surfaces of joint mating parts are developed. The basic requirements for the regulation channels of control system that ensure the quality of hydropress fits during automated assembling are established.
\end{abstract}

\section{Introduction}

One of the most advanced technologies for obtaining joints with tension is the hydropress assembling method, that is based on creating an oil layer under high pressure between the contacting surfaces of the assembled parts, as a result of which the relative displacement of the mating surfaces of the shaft and bush takes place fluid and boundary friction $[1,2]$.

Increasing the performance of assembling, its stability, as well as ensuring the quality of hydropress joints are possible on the basis of automation of assembling process, that allows to fully realize the advantages of this method [3].

\section{Hydropress method for interference fits creating}

Increased attention to the hydro-press assembling technology is due to its advantages such as $[4,5]$ :

1) possibility of assembling high-strength joints with large tightnesses;

2) significant (10-15 times) reduction of pressing forces compared to the mechanical assembling method; reduction the power of pressing equipment;

3) lower energy consumption compared to thermal assembling methods;

4) no damage to the mating surfaces.

From the point of view of hydropress assembling process automation, the main problem

*Corresponding author:ms_istu@mail.ru 
is a great complexity due to the need for high-pressure pumps with hydraulic armature and pressure regulators and oil flow with an operating pressure of more than $200 \mathrm{MPa}$.

To increase the technological capabilities of hydropress method, mechanized highpressure pumps (with pneumatic or electromechanical drives) have been developed and are used. However, it is not possible to avoid a discrete supply of lubricant, that's why the process stability decreases [6].

To ensure the liquid friction mode is necessary to meet the following requirements:

1) the entry chamfers of the mating parts must be $15^{\circ}$ for the male part and $30^{\circ}$ for the female part;

2) the initial preload force of mating parts must ensure the tightness of working cavity over the entire cylindrical mating surface. At the same time, the contact pressure on the mating chamfer from the preload force must be uniform;

3) the relative parts skewing to each other should be eliminated on the press-in length no more than 0.1 of it.

At automation of hydropress assembling the technological schemes for oil supply from the joint end, as well as a differential method that eliminates of high-pressure pumps, are more perspective

The technological scheme with oil supply from shaft end is adopted as the object of automation (Fig 1).

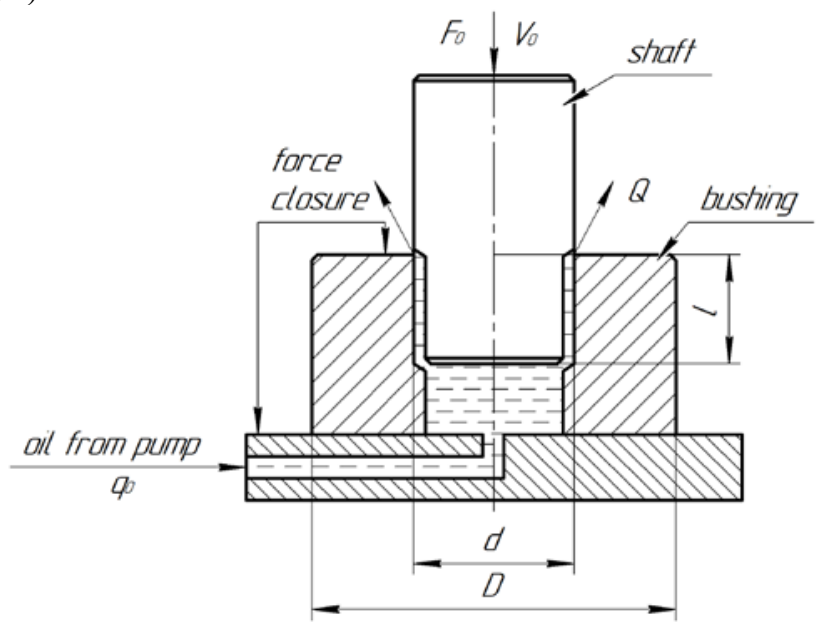

Fig 1. Flow diagram with oil supply from the shaft end

$\mathrm{d}_{1 \mathrm{q}}$ - diameter of the deformed shaft, $\mathrm{F}_{0}$-axial force, 1 - pressing length, $\mathrm{q}_{0}$ - oil pressure, $\mathrm{Q}$ - oil volume in the working cavity

The assembling parts: shaft 1 and bushing 2 are shown in the position after shaft preloading with a force of $F_{0}$. The choice of this scheme is due to the fact that the liquid friction mode is guaranteed, but at the same time removing of significant oil volume from working area is required.

\section{Technological equipment and automation aspects of interference fits hydropress assembling}

\subsection{Press equipment and its applicability for hydropress assembling}

It is necessary to create an axial force when assembling of hydropress joints with tension, 
Special or universal (pneumatic, hydraulic, pneumohydraulic, shock-pulse, electromagnetic, electromechanical (crank)) presses are widely used for this purposes.

The required force created by the press is determined based on tension, the interface diameter and lubrication supply scheme (in this case, the force reserve coefficient is assumed to be equal to 1.5-2) [7,8]. All types of pressing equipment are applicable for hydropress assembling depending on the required force.

Pressing equipment, as a rule, does not have the required positioning accuracy and movement uniformity of press working body and does not allow to control the hydropress assembling process. Because it does not have speed, pressure and pressing force feedbacks, therefore does not provide the required modes of liquid friction. The oil film breaks and the parts set are possible when using unregulated presses during the assembly process, that leads to scuffing on the mating surfaces, a decrease in the bearing capacity of the joint, and, consequently, to a production defect.

The disadvantages of mass-produced presses in relation to hydropress assembling are as follows: regulation is carried out by force and speed regulation is difficult in pneumatic and hydraulic presses as high - precision regulating pneumatic and hydraulic equipment is required, also there is no necessary nomenclature of equipment for force. Pneumohydraulic presses have the same problems also. Using of shock-pulse presses is associated with the occurrence of hydraulic shocks in the hydraulic system for hydropress assembling. Electromagnetic presses have low effort, low travel and poor handling. A significant disadvantage of considered presses is the speed control inability of press rod during assembling.

An analysis of press equipment showed that the press equipment with an electric drive are most satisfied to control the hydropress assembling process.

Electromechanical presses based on servos [9] have a high speed, stepless speed control in a wide range, high accuracy positioning of the output element under changing loads, that will positively affect on the stability of the liquid friction mode of the hydropress assembling process.

\subsection{Features of hydraulic press assembly automation}

A qualitative analysis of the existing press equipment used in hydropress assembling showed that it does not provide the control of process assembling modes and required accuracy of movement, as a result of which it becomes necessary to develop specialized press equipment.

An important feature of tight joints assembling automation is the provision of relative centering of the mating parts. Errors made during pressing are often the cause of scuffing in dry friction areas [10].

There may be inaccuracies in the coupling of parts during the assembling process. Small relative misalignments of parts can be cause of poor assembly due to the oil layer rupture and the presence of scuff marks.

Also should take into account that a delay at the end of the assembling is required for the oil drain out from the interface zone. In addition, it is possible to depress the part by a certain value of $\Delta \mathrm{Zdp}$ after removing the axial load, it depends on a number of design and technological factors. The load maintaining for some time after the assembling completion significantly reduces the spin-out .

To minimize of distortion are necessary to ensure the smooth shaft compression to the bushing, the presence of appropriate chamfers or entry chamfers on the parts.

Elimination of errors of initial basing and final positioning is carried out by design and technological solutions and exposure of the hydropress connection after assembly. 


\subsection{Requirements of automated hydropress assembling to process equipment}

The basic requirements for process equipment and control system are set on the basis of hydropress assembling process analysis: the presence of oil pressure feedback; the presence of position feedback; regulation of the movement speed from 0.5 to $50 \mathrm{~mm} / \mathrm{s}$ using forward and reverse feedbacks; the developed force should ensure the creation of necessary pressure and the liquid friction mode; the working oil pressure should not cause plastic deformations in the fits parts and technological equipment.

\section{Technological equipment and automation aspects of interfence fits hydropress assembling}

A physical model of the hydropress assembing process (technological scheme with oil supply from the joint end) is shown in Fig 2.

The main control effect of this assembling process is the shaft movement speed $\mathrm{V}_{0}$ relative to the bushing .

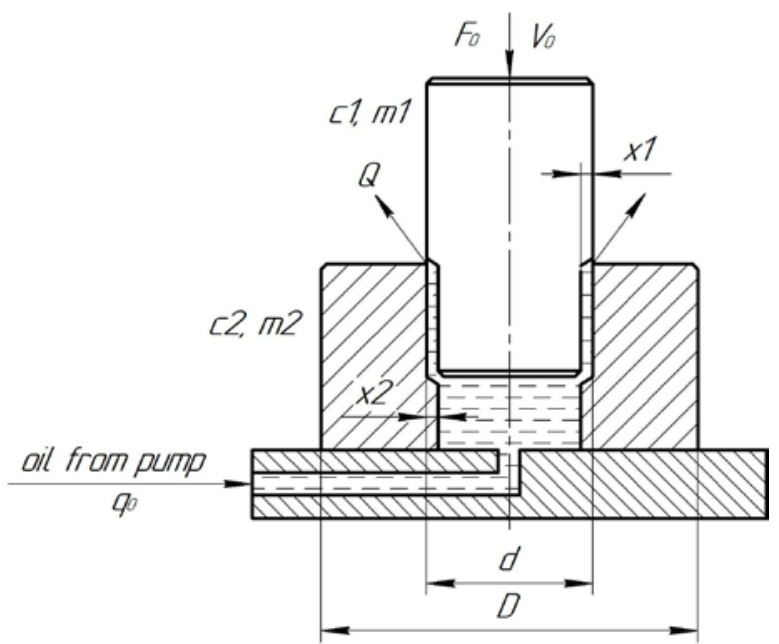

Fig. 2. Physical model of the tight joints hydropress assembing process

The physical model uses the following notation: $\mathrm{c}_{1}, \mathrm{c}_{2}-$ the given stiffness coefficients of shaft 1 and bushing 2; $\mathrm{d}$ - interface diameter; $\mathrm{D}$ - outer diameter of the bushing; $\mathrm{F}_{0}-$ pressing force; $\mathrm{m}_{1}, \mathrm{~m}_{2}$ - reduced mass of shaft 1 and bushing $2 ; \mathrm{q}$ - oil pressure; $\mathrm{Q}_{0}$ - oil consumption; $\mathrm{x} 1$-shaft diameter reducing; $\mathrm{x} 2$ - bushing diameter increasing.

Equations (cross-press component) connects the variables $\mathrm{F}_{0}, \mathrm{x}_{1}, \mathrm{x}_{2}$, can be represented as (in general):

$$
\begin{aligned}
& m_{1} \cdot\left(d^{2} x_{1} / d t^{2}\right)+b_{1} \cdot\left(d x_{1} / d t\right)+c_{1} x_{1}=F_{P} \\
& m_{2} \cdot\left(d^{2} x_{2} / d t^{2}\right)+b_{2} \cdot\left(d x_{2} / d t\right)+c_{2} x_{2}=F_{P}
\end{aligned}
$$

where $b_{1}, b_{2}$ - the coefficients of viscous friction of the shaft 1 and the sleeve $2 ; c_{1}, c_{2}$ - the reduced stiffness coefficients of shaft 1 and bushing $2 ; F_{P}-$ the pressing force required for the joint assembling is calculated as: 


$$
\begin{aligned}
& F_{0}=F_{L}+F_{q} \\
& F_{L}=q \cdot n \cdot d \cdot l \cdot f \\
& F_{q}=q \cdot\left(\pi d^{2}\right) / 4
\end{aligned}
$$

where $F_{L}$ - force in the area of liquid friction; $F_{q}$ - force from oil pressure; $q$ - oil pressure; $\mathrm{f}$ - coefficient of friction; 1 - interface length.

In turn, $\mathrm{q}=\mathrm{f}(\mathrm{t}), \mathrm{F}=\mathrm{f}(\mathrm{t})$, that leads to non-linearities during pressing.

The maximum pressure value $\mathrm{q}_{\max }$ is limited by the occurrence of plastic deformation:

$$
q_{\max } \leq 0.58 \cdot \sigma_{y} \cdot\left[1-(d / D)^{2}\right]
$$

where $\sigma_{\mathrm{Y}}$ - yield strength of sleeve material.

It is necessary to control the pressing speed $\mathrm{V}_{0}$ ensuring the constant operating oil pressure $\mathrm{q}_{\mathrm{op}}$ and, thereby, the mode of liquid friction when using the technological scheme with oil supply from the joint end,

The general control algorithm for the hydropress assembling process of the fits group is shown in Figure 3.

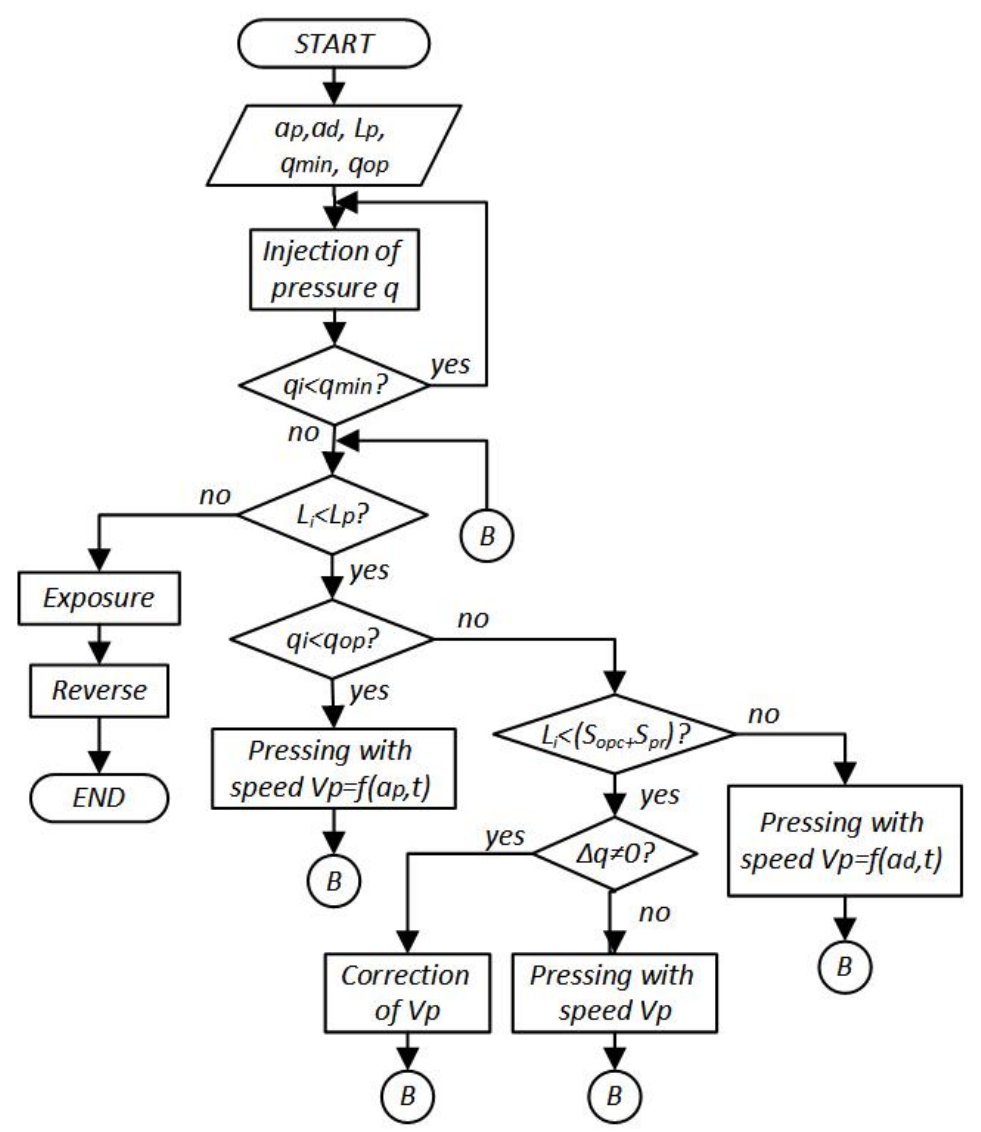

Fig. 3. Control algorithm of hydropress assembling (automatic mode)

The following notation are used in the algorithm:

$a_{p}$ - pressing acceleration, $a_{d}$-deceleration, $L_{i}-$ pressing length at $i-$ time moment, $L_{p}-$ pressing length, $\mathrm{q}_{\mathrm{i}}$ - oil pressure at $\mathrm{i}$ - time moment, $\mathrm{q}_{\text {min }}$ - initial (starting) oil pressure, 
$\mathrm{q}_{\mathrm{op}}-$ operating oil pressure, $\mathrm{S}_{\mathrm{pr}}$ - length of the pressure regulation section, $\mathrm{S}_{\mathrm{opc}}-$ length of operating pressure creation section, $\mathrm{t}-$ time, $\mathrm{V}_{\mathrm{p}}$ - pressing speed.

The control algorithm maintains the operating oil pressure $\mathrm{q}_{\mathrm{op}}$ in the control section (semi-fluid friction section) by changing $\mathrm{V}_{0}$ that provides the required modes of hydropress assembling.

The presented physical, mathematical models and algorithm regulate the process of liquid friction and the formation of an oil layer between the contacting surfaces. The calculated values of the assembling parameters require the adjustment, the coefficients of controlled parameters must have a sufficient margin due to rheological changes in the working fluid under high pressure and high non-linearity of the assembly process flow.

\section{Technological justification of requirements for regulatory channels}

Hydropress assembling has some technological and physical features that must be taken into account when justifying the requirements for control channels.

It is necessary to systematically obtain the information that characterizes the true state of the process at each time point when assembling the fits in automatic mode. The received information should be complex and continuously available for computing during the process. At the same time, the decision-making process should have a minimum delay time [11].

The analysis has demonstrated that four closed control loops with subordinate control are necessary to obtain the complete information about the assembling process progress and ensure timely regulation of its parameters:

- position loop that implements a real-time control of the shaft position;

- speed loop that provides the specified (or maximum possible) performance of the assembly operation. On the one hand, the assembling speed determines the performance, and on the other hand, it is associated with the control effect on the control object, since it directly determines the quality of the resulting joints when assembling according to the scheme with oil supply from the connection end, as a result, the speed $V_{0}$ should be controlled;

- pressure loop that provides modes and conditions for hydropress assembling. The oil pressure $\mathrm{q}$ during assembling is a critical parameter that determines the load-bearing capacity of both: the joint itself and the tooling elements, and therefore characterizes the quality of connections with guaranteed tightness. Depending on the selected oil supply scheme, pressure information has a restrictive (differential method, oil supply from the end) or regulatory (supply from the end) function;

- force loop that performs an informational role. By the value of current pressing force $\mathrm{F}_{0}$, you can judge what stage the assembling process is at the current time. The pressing force can be considered as an output value that determines individual indicators of the quality and assembling process of the connections that being made.

\section{Conclusion}

To effective quality ensure of the assembled hydropress joints and the productivity of their assembling the technological equipment providing the stabilization of the resulting fits quality indicators are perspective.

The analysis has revealed that the providing of automated hydropress assembling is most satisfied by mechatronic systems with a large number of feedbacks (pressure, position, speed, force) and movement control of press rod, in particular, press equipment with an electric drive that provides stabilization of the quality indicators of the resulting 
fits.

The developed mathematical models and algorithm that regulate the process of liquid friction and the formation of an oil layer between the contacting surfaces of the mating parts of the joint are the basis for the design of an automatic control system for the hydropress assembling of joints with tension.

\section{References}

1. I.V. Abramov, Research and improvement of the hydropress method of assembly of joints with tension: abstract of the cand. of tech. sci. dis. (Perm, 1970)

2. K.A. Glukhova, Investigation of the technological parameters of the hydro-press assembly of joints with tension at increased formation speeds: abstract of the cand. tech.sci. dis (Chisinau, 1975)

3. E.S. Grechishchev, A.A. Ilyashenko. Connections with tightness: Calculations, design, manufacturing (Mashinostroenie, Moscow, 1981)

4. I.V. Abramov, F.F. Fattiev, V.A. Dulotin, High-stress connections with guaranteed tension. (ISTU publishing, Izhevsk, 2002)

5. B. F. Fedorov, Rational method of parts decompressing and pressing (Mashgiz, Moscow, 1955)

6. A.V. Schenyatsky, I. V. Abramov, K. A. Glukhova, Theory and technology of hydropress fits (ISTU publishing, Izhevsk, 2012)

7. A.N. Banetov, E.N. Lansky, Forging and stamping equipment (Mashinostroenie, Moscow, 1982)

8. Yu.A. Bocharov, Screw presses (Mashinostroenie, Moscow, 1976)

9. M.P. Novikov, Fundamentals of machine and mechanism assembly technology, (Mashinostroenie, Moscow, 1980)

10. A.F. Novikov, Adaptive control of the assembly process of longitudinal-press joint: abstract of the cand. of tech. sci. dis. (Samara, 2002)

11. A.I. Abramov, I.V. Abramov, A.V. Romanov, Scientific and technical aspects of automation hydraulic connection Assembly with interference, Assembly in mechanical engineering, instrument making. v. 1, pp. 16-18 (2013) 